\title{
Dêixis pessoal e temporal: aspectos sociointeracionais e sociodiscursivos
}

\author{
Leonor Werneck dos Santos ${ }^{1}$ \\ Margareth Morais ${ }^{2}$
}

\begin{abstract}
Resumo: O objetivo deste artigo é discutir o fenômeno da dêixis pessoal e temporal, trazendo à tona aspectos sociointeracionais e sociodiscursivos que ampliam a compreensão do papel dos elementos dêiticos. Partiremos de um breve histórico da literatura tradicional sobre dêixis (LYONS, 1977; FILLMORE, 1984; BUHLER, 1977), para chegar a estudos mais recentes (FONSECA, 1992; CORNISH, 2007; SANTOS E CAVALCANTE, 2014; dentre outros), que contemplam questionamentos acerca do caráter textual-discursivo do fenômeno. Com base em Marmaridou (2001), Maalej (2011) e Cabral e Santos (2016), analisaremos notícias esportivas mostrando como a dêixis atua na construção do texto, marcando posicionamentos ideológicos e construindo sentidos que vão além da classificação tradicional.
\end{abstract}

Palavras-chave: Linguística de Texto. Dêixis. Construção de sentidos.

\begin{abstract}
The objective of this article is to discuss the phenomenon of personal and temporal deixis, emphasizing sociointerational and sociodiscursive aspects that broaden the understanding of the role of the deitic elements. We will start from a brief history of the traditional literature on deixis (LYONS, 1977; FILLMORE, 1984; BUHLER, 1977) to arrive at more recent studies (FONSECA, 1995, CORNISH, 2007, SANTOS AND CAVALCANTE, 2014; among others), that contemplate questions about the textual-discursive character of the phenomenon. Based on Marmaridou (2001), Maalej (2011) and Cabral and Santos (2016), we will analyze sports news showing how deixis acts in the construction of the text, marking ideological positions and constructing meanings that go beyond the traditional classification.
\end{abstract}

Keywords: Text Linguistics. Deixis. Meaning construction.

\footnotetext{
${ }_{1}$ Professora Associada IV da Universidade Federal do Rio de Janeiro (Faculdade de Letras), atua na graduação, em Letras e Comunicação Social, e no mestrado e doutorado em Letras Vernáculas. Membro do GT de Linguística de Texto e Análise da Conversação da ANPOLL.

2 Doutora e Mestre em língua portuguesa pela Universidade Federal do Rio de Janeiro (UFRJ). Professora efetiva de Língua Portuguesa e Literatura brasileira do Instituto Federal de Educação, Ciência e Tecnologia do Rio de Janeiro (IFRJ).
}

Este artigo está licenciado sob forma de uma licença Creative Commons Atribuição 4.0 Internacional, que permite uso irrestrito, distribuição e reprodução em qualquer meio, desde que a publicação original seja corretamente citada. https://creativecommons.org/licenses/by/4.0/deed.pt BR. 
Sommario: L'obiettivo di questo articolo è quello di discutere il fenomeno dei deissi personale e temporale, portando in primo piano aspetti sociointerrazionali e sociodiscursivi che ampliano la comprensione del ruolo degli elementi dei. Inizieremo da una breve storia della letteratura tradizionale sui deissi (LYONS, 1977; FILLMORE, 1984; BUHLER, 1977), per arrivare a studi più recenti (FONSECA, 1992; CORNISH, 2007; SANTOS E CAVALCANTE; tra gli altri) che contemplano domande sul carattere testuale-discorsivo del fenomeno. Basato su Marmaridou (2001), Maalej (2011) e Cabral e Santos (2016), analizzeremo le notizie sportive mostrando come la deissi agisce nella costruzione del testo, segnando posizioni ideologiche e costruendo significati che vanno oltre la classificazione tradizionale.

Palore chiave: Linguistica di testo. Deissi. Costruzione di sensi.

\section{Introdução}

Desde a década de 1960, com publicações de Benveniste (1991[1966]), Fillmore (1971), Lyons (1977), Buhler (1977), dentre outros autores, estudos sobre a dêixis têm preocupado linguistas, geralmente em uma perspectiva de descrição e classificação dos dêiticos. Ultimamente, porém, pesquisadores como Fonseca (1992), Marcuschi (1997), Marmaridou (2001), Cornish (2007), Maalej (2011), Santos e Cavalcante (2014) e Cabral e Santos (2016), apenas para citar alguns, vêm discutindo o status textual-discursivo da dêixis.

O objetivo deste artigo, portanto, é colaborar para o debate sobre o fenômeno da dêixis, trazendo à tona aspectos sociointeracionais e sociodiscursivos. Citaremos exemplos de dêixis pessoal e temporal em notícias esportivas referentes a jogos da Copa do Mundo de 2014, publicadas nos jornais O Globo e Lance!, e, para a análise dos dados, seguiremos a proposta de Morais (2017). Pretendemos mostrar como a dêixis atua na construção do texto, marcando posicionamentos ideológicos e construindo sentidos que vão além da classificação tradicional. 


\section{Dêixis: da perspectiva tradicional à sociointeracional}

Tradicionalmente, os estudos sobre a dêixis, em comparação com as anáforas, trazem a ideia de que esse fenômeno daria conta de processos coesivos "fora do texto", enquanto as anáforas seriam os processos que ocorrem "dentro do texto". Atualmente, porém, os processos referenciais têm sido considerados em uma perspectiva sociognitivo-interacional, o que torna a fronteira entre anáfora e dêixis mais tênue, como veremos a seguir. Para Santos e Cavalcante (2014, p. 226),

Essa perspectiva contemporânea de referenciação considera que o objeto de discurso vai sendo construído durante a enunciação, num movimento sociocognitivo de ativação de conhecimento prévios. Dessa forma, o contexto passa a ser constitutivo dos fenômenos referenciais.

$\mathrm{Na}$ perspectiva tradicional da dêixis, considera-se a origo, a perspectiva do falante, para determinar coordenadas de pessoa, tempo e espaço - uso de pronomes demonstrativos "este/aquele", pessoais "eu/tu", advérbios "aqui/aí/lá", por exemplo -, como acontece nos estudos de Lyons (1977). Convém ressaltar que, nesse momento das pesquisas, a noção de texto ainda correspondia à visão de texto como um "produto", que continha em si todas as informações necessárias para sua interpretação. Desse modo, os processos coesivos podiam ser claramente separados em dentro e fora do texto (cf. EHLICH, 1982). 
Para Buhler (1982), a marcação do campo dêitico sustenta-se em um sistema de orientação subjetiva em que algumas expressões se referem a um campo dêitico na linguagem, que contém marcações referentes ao lugar, ao espaço e ao tempo. Os estudos desse autor caracterizam a dêixis como um fenômeno linguístico, demonstrando o papel central desse fenômeno na linguagem verbal. $\mathrm{O}$ autor atribui à dêixis um campo mostrativo da linguagem em que o falante seria o eixo norteador.

Fillmore (1984, p.61) também define a dêixis tendo em vista o contexto da enunciação, mostrando que a interpretação dos eixos dêiticos está atrelada ao momento enunciativo:

Dêixis é o nome dado a propriedades formais de enunciados que são determinadas por certos aspectos do ato de comunicação em que as declarações em questão podem desempenhar um papel e que são interpretadas pelo conhecimento. Essas declarações incluem (1) a identidade dos interlocutores em uma situação de comunicação, denominada pelo termo dêixis de pessoa; (2) o lugar ou lugares em que esses indivíduos estão localizados, para o qual temos o tempo dêixis de lugar; (3) o tempo em que o ato de comunicação toma lugar (...).

Para esses autores, as marcas dêiticas funcionariam, então, como um sistema de coordenadas para auxiliar a situar a perspectiva do falante no momento da enunciação. Tais marcas são gatilhos que acionam um sistema de orientação que permite aos participantes do ato de comunicação inter-relacionar referências dêiticas de pessoa, tempo e espaço, criado dentro do próprio enunciado. Assim, um determinado elemento só pode ser considerado dêitico se for possível tomar como ponto de origem quem é o falante e onde ele se localiza no 
tempo/espaço de sua fala no contexto. Um enunciado como "eu preciso que você vá lá agora", por exemplo, exige que o coenunciador conheça a informação sobre quem é o falante e sua localização no espaço e no tempo; assim os pronomes "eu/você" e os advérbios "lá/agora" são expressões dêiticas. Desse modo, diferentemente do que acontece com os processos anafóricos, os dêiticos podem ser definidos por sua capacidade de criar uma relação entre o cotexto e a situação comunicativa em que se encontram os participantes da enunciação.

Para Fiorin (1996, p. 56), os dêiticos são interpretados com referência à situação enunciativa, pressuposta ou explicitada no texto pelo narrador; já os elementos anafóricos "são compreendidos em função de marcas temporais e espaciais instaladas no enunciado e de actantes do enunciado anteriormente mencionados".

Todas essas definições clássicas de dêixis convergem para o fato de que se trata de um fenômeno que só ocorre na enunciação e diz respeito ao funcionamento da língua no momento da enunciação. Nessa perspectiva, texto e discurso parecem se opor, e a dêixis surge como uma marca textual da enunciação. Entretanto, os estudos atuais sobre processos referenciais, dentre os quais a dêixis se insere, consideram o texto de maneira processual, observando aspectos sociocognitivos e interacionais, o que destoa dessa concepção tradicional de dêixis como algo que aponta para "fora" do texto.

Para Fonseca (1992, p.136, grifos da autora):

A relação de dependência que liga o discurso ao seu contexto é uma relação reversível: se a linguagem é dependente do contexto, também se pode dizer que o contexto é dependente 
da linguagem na medida em que é por ela criado. Trata-se, pois, de uma relação de interdependência. Uma relação dinâmica e dinamizadora: o discurso e o contexto não são objectos estáveis, são processos entre os quais se estabelece uma interacção construtiva.

Postura semelhante assume Schiffrin (1990, p. 246), para quem a dificuldade em impor limites entre anáfora e dêixis reside no fato de ambos os processos parecerem se misturar em exemplos como "Eu nasci em Londres e vivi aqui/lá minha vida toda": os termos grifados associam-se anaforicamente em relação a Londres e de maneira dêitica quanto ao enunciador - demonstrando sua proximidade ou distância em relação à capital britânica.

Essa concepção mesclada entre anáfora e dêixis retoma, de certa forma, o que apontam Halliday e Hasan (1976, p. 37, tradução nossa) a respeito da flutuação entre os fenômenos:

um item referencial não é intrinsecamente exofórico ou endofórico; ele somente é 'fórico' - simplesmente tem a propriedade de referir. Qualquer referência pode ser de um tipo ou de outro, ou pode também ser, a um só tempo, de ambos os tipos. ${ }^{3}$

O caráter híbrido entre anáfora e dêixis também é destacado por Cornish (2007, p. 1, tradução nossa), para quem "tanto a anáfora como a deixis funcionam ao nível da organização da memória, permitindo que

\footnotetext{
3 "A reference item is not of itself exophoric or endophoric; it is just 'phoric' - it simply has the property of reference. Any given instance of reference may be either one or other, or it may even be both at once".
} 
o falante a gerencie orientando o processamento do destinatário dos segmentos recebidos de um texto"4.

Analisando a dêixis como estratégia persuasiva em anúncios publicitários - textos fortemente marcados por aspectos culturais -, Pardillos (1995, p. 6o) observa que os mecanismos dêiticos envolvem os papéis desempenhados pelos interlocutores. Para o autor, os anúncios despertam nosso lado egoísta, ao contrário de textos políticos, que apontam para o "bem comum" - como os analisados por Cabral e Santos (2016) e por Maalej (2013).

Hanks (2008) e Maalej (2013) defendem que a dêixis desempenha um papel pragmático na interação social no discurso. Para Maalej (2013), os pronomes, por se referirem a pessoas e grupos, implicam relações de poder, por isso, além de uma dimensão discursiva, pode-se falar também de uma dimensão política. Assim, mesmo o 'eu', além de indicar o enunciador, "pode operar como um meio de construção do Outro: pode estar em oposição a qualquer 'você' ou 'eles' da mesma forma que 'nós"' (MAALEJ, 2013, p. 639, tradução nossa)5.

Cabral e Santos (2016, p. 30) destacam que é comum pesquisas sobre dêixis enfatizarem aspectos mais linguísticos, estruturais, como uso dos pronomes demonstrativos e advérbios, em vez de questões textual-discursivas. As autoras alertam, porém, que, "quando analisamos alguns textos, como discursos de políticos e a carta-

\footnotetext{
4 "Both anaphora and deixis operate at the level of memory organization, enabling the speaker to manage it by guiding the addressee's processing of the incoming segments of a text".

5 "l' can also operate as one half of a construction of the Other: It can stand in opposition to any 'you' or 'they' in the same way that 'we' does".
} 
testamento de Getúlio Vargas, podemos observar aspectos sobre a dêixis que denotam seu papel na arquitetura argumentativa”. Cabral e Santos (2016, p. 29), ao analisarem a dêixis de pessoa na carta testamento, destacam que

Quando, no processo de referenciação, o objeto de discurso se identifica com "eu", o processo toma uma relação com a questão da subjetividade $\mathrm{e}$, necessariamente, com a intersubjetividade. A dêixis, por exemplo, nos remete à questão do sujeito enunciador e sua relação com os demais sujeitos inseridos no texto - eu, tu e ele -, o que nos conduz à problemática da enunciação e, por conseguinte, aos postulados de Benveniste.

Por isso, Cabral e Santos (2016, p. 33) concluem que

O EU se constrói não como oposição à za pessoa, como se poderia esperar, mas em oposição aos OUTROS, inimigos, à espreita para tomar o poder e maltratar o POVO/VÓS, que precisa ser protegido. (...) Assim, na carta testamento, os dêiticos de pessoa também parecem demonstrar muito mais que os integrantes do jogo discursivo, pois denotam jogos de força, marcando a disputa pelo poder. Desempenham, portanto, papel persuasivo, marcando o posicionamento do escriba diante dos demais interlocutores, incluindo-os ou não no discurso e colocando-se como EU-salvador e mártir da pátria.

Vemos, portanto, que o fenômeno da dêixis vem preocupando linguistas de várias vertentes teóricas, incluindo ou não aspectos associados à subjetividade - como encontramos em Benveniste (1991[1966]) -, questionando o limite entre anáfora e dêixis e sugerindo diversos papéis textual-discursivos. 


\section{Tipos clássicos de dêixis}

\section{Dêixis pessoal (e social)}

Ao pensar na dêixis pessoal, logo lembramos dos pronomes pessoais, que representam uma categoria prototípica da dêixis de pessoa. Os pronomes "eu/tu/você" estariam relacionados à noção de pessoa, e pronomes de terceira pessoa estariam ligados a um uso anafórico, ou seja, a não pessoa, delimitando, portanto, uma categoria de pronomes dêiticos e outra de pronomes anafóricos.

Estudos que mostram o valor dêitico dos pronomes são recorrentes; no entanto, poucos trabalhos chamam atenção para a dimensão discursiva e, por vezes, ideológica do emprego do dêixis pessoal. De acordo com Maalej (2013), em seu estudo sobre o uso dos pronomes Eu/Nós/Vocês em discursos de Osni Mubarak como presidente do Egito, os dêiticos de pessoa devem ser analisados conforme suas dimensões discursivas e ideológicas, pois, além do uso discursivo, os pronomes têm demonstrado "uma importante dimensão ideológica":

\footnotetext{
Enquanto o usuário do "eu" está ancorado no discurso como egocêntrico e egocêntrico, "nós" constrói duas relações sociais diferentes. Pennycook (1994, p. 175) argumenta que "nós" é sempre simultaneamente inclusivo e exclusivo, um pronome de solidariedade e de rejeição, de inclusão e exclusão. Por um lado, define um "nós" e, por outro, define um "você" ou um "eles" (MAALEJ, 2013, p.639, tradução nossa). ${ }^{6}$
}

\footnotetext{
${ }^{6}$ While the user of "l" is anchored in discourse as egocentric and self-centered, "WE" constructs two different social relations. Pennycook (1994: 175) argues that "we' is always simultaneously inclusive and exclusive, a pronoun of solidarity and of rejection, of inclusion and exclusion. On the one hand it defines a 'we', and on the other it defines a 'you' or a 'they.'
} 
Desse modo, os pronomes pessoais, além de anunciar o enunciador, podem funcionar como uma forma de construir o outro. Portanto, o "eu"/"você", nós/"eles" devem sempre ser entendidos com referência a outros pressupostos sobre quem está sendo definido como o "nós" do qual o "você" e o "eles" diferem.

Cabral e Santos (2016), abordando as estratégias argumentativas presentes na carta testamento de Getúlio Vargas, também demonstram como se constitui a imagem do "eu", numa relação intersubjetiva com "o povo", a quem se dirige, e marcando o confronto com seus opositores, de quem se distancia. As autoras mostram que, na carta testamento, os dêiticos de pessoa também parecem demonstrar muito mais que os participantes do jogo discursivo, denotando jogos de força, que marcam a disputa pelo poder. Esses recursos marcam o posicionamento do autor da carta diante dos demais interlocutores ora incluindo-os ora excluindo-os - e projetando-se como um mártir da pátria. Cabral e Santos concluem que os mecanismos dêiticos de pessoa constituem marcas de subjetividade e podem apresentar um caráter persuasivo, contribuindo, assim, para a argumentatividade do texto.

Já a dêixis social consiste no emprego de formas que representam relações sociais estabelecidas no ato da conversação. São expressões que têm em vista contextos de maior ou menor formalidade, polidez e até mesmo intimidade, bem como propósitos comunicativos do contexto de comunicação. Alguns exemplos desses casos de dêixis podem ser observados no emprego dos pronomes de tratamento, como no francês "tu/vous", ou em português no emprego das formas 
"senhor/você", em que a escolha de determinada forma acarreta maior ou menor intimidade entre os interlocutores.

Para Marmaridou (2000, p.98) é difícil separar a dêixis de pessoa e a social, pois esta "fornece ancoragem para linguagem em seu contexto interacional imediato de uso". Alguns linguistas como Fonseca (1992), assim como Santos e Cavalcante (2014), acreditam que a dêixis social deve ser entendida como um subtipo da dêixis de pessoa, posição com a qual concordamos, pois o uso de tais formas pessoais está atrelado aos propósitos comunicativos da situação enunciativa em questão. Desse modo, privilegia-se o papel discursivo da escolha dessas formas.

\section{Dêixis temporal e espacial}

Segundo Cavalcante, Custódio Filho e Brito (2014), os dêiticos temporais e espaciais são indicadores de ostensão, porque apontam para um lugar e fixam uma fronteira de tempo e no espaço que toma por referência o posicionamento do "eu" no momento da enunciação.

Uma expressão temporal não vai constituir um exemplo de dêixis temporal se não tomar como referência o momento em que se encontra o locutor. De modo semelhante, os dêiticos espaciais marcam as noções de proximidade/distância do locutor em relação a um dado referente. Tais mecanismos apontam para um lugar situado e relacionado com quem produz o enunciado. Do mesmo modo que ocorre na dêixis temporal, nem todas as expressões que denotam lugar serão necessariamente dêiticos de espaço. Assim, só será considerada dêitica 
a expressão que, para identificar o referente, necessite do falante como ponto de origem.

Santos e Cavalcante (2014, p.231) apresentam um exemplo em que ocorrem as categorias de tempo e espaço, porém, a relação com o centro dêitico não parece ser a mesma nos dois casos: "Nossa acredita, até hoje eu não consigo mais ficar aqui no orkut, fiquei muito mal mesmo por terem excluído meu perfil... eu tinha muitas coisas escritas [...]". Nesse exemplo, a expressão "até hoje" (e também o pronome "eu") está diretamente ligada ao sujeito enunciador, pois, sem esse conhecimento, não podemos precisar o limite temporal estabelecido. No entanto, o advérbio "aqui" relaciona-se à expressão "no Orkut", tomado como um lugar, dependendo menos, portanto, do enunciador para sua interpretação.

\section{Dêixis “impura”: memorial e textual}

Segundo Lyons (1977), além dos casos tradicionais referentes a lugar, espaço e pessoa, chamados de "dêixis pura", há também os casos de "dêixis "impura", como a dêixis social, a de memória e a textual (alguns autores a chamam de "dêixis discursiva"), que, segundo o autor, estariam fora das classificações tradicionalmente reconhecidas como dêiticas. Como já apontamos acima que a dêixis social configura um subtipo da dêixis de pessoa, vamos nos deter à discussão dos casos de dêixis de memória e textual/discursiva.

Apothéloz (2003) chama de dêitico de memória um tipo de dêixis que tem por objetivo fornecer indícios ao coenunciador de que ele deve 
buscar o objeto aludido em conhecimentos que os participantes da comunicação compartilham. Assim, a dêixis de memória, de acordo com Cavalcante, Custódio Filho, Brito (2014), convoca o leitor a procurar na memória discursiva que o texto recria um objeto de discurso que é evidente para o enunciador como se já tivesse sido mencionado no contexto.

Os autores afirmam ainda que a presença de demonstrativos é fundamental nesse processo, analisando um exemplo retirado da rede social Facebook: "E_aquela hora que vc pensa em comer algo e descobre: só terá comida se vc fizer...ahaaahaaaaa..." (cf. CAVALCANTE, CUSTÓDIO FILHO, BRITO, 2014, p. 96). A expressão em itálico convida o leitor a investigar o momento apontado no texto, levando o destinatário a ter a impressão de que essa informação é perfeitamente acessível na memória discursiva.

Já a dêixis discursiva (cf. MARCUSCHI, 1997) ou textual, de acordo com Cavalcante (2011), consiste nas orientações presentes dentro do cotexto que indicam/apontam para posições dentro do texto, tendo como origem a enunciação e a organização das palavras. Expressões como "as palavras acima" ou "no capítulo anterior", por exemplo, desempenham uma função de organizadores textuais. Nesses casos, o procedimento dêitico seria o de fazer o leitor focalizar o espaço dêitico que seria o texto.

Em relação à definição de dêixis textual/discursiva, vale salientar que Marcuschi (1997) e Cavalcante (2011) retomam Fillmore (1984) e Ehlich (1982). Fillmore afirma que esse tipo de dêixis se refere a uma porção do discurso em andamento; já Ehlich destaca o fato de a dêixis 
orientar o foco de observação e atenção do leitor, mesmo apontando para algo não pontualmente identificável.

Entretanto, Santos e Cavalcante (2014, p. 232) comentam alguns exemplos, listados abaixo, questionando o fato de, tradicionalmente, serem classificados como dêixis textual:

(a) X says) - I've never ever seen him. (Y answers) - That's a lie. (X diz - Eu nunca o tinha visto antes / e Y responde - Isso é uma mentira.)

(b) Além de não fazer mal algum, muitos insetos podem ser tão nutritivos - e saborosos quanto vários outros bichos que colocamos no prato todos os dias. "O nojo que nós, ocidentais urbanos, temos por esses seres é puramente cultural", diz Bill Yosses, chef do badalado restaurante nova-iorquino Citarella.

(c) Os desenhos que ilustram esta reportagem fazem parte do conjunto de 31 imagens selecionadas por Graça Pizá para ilustrar o que batizou de "vocabulário ilustrado dos afetos emparedados" - uma síntese dos sentimentos mais frequentemente expostos por seus pequenos clientes.

Para as autoras, apenas (c) pode ser considerado dêixis textual, já os outros exemplos (a e b) são, respectivamente, anáfora encapsuladora e anáfora direta. Esse entrelaçamento entre dêiticos textuais e anáforas encapsuladoras acontece também por haver uma tendência nos estudos mais tradicionais a restringir o estudo da dêixis ao estudo do uso dos demonstrativos ou, pelo menos, a valorizar a presença desse demonstrativo como um indicador de coordenada dêitica, o que fez com que casos como o do exemplo (a) fossem colocados no rol da dêixis textual e não do encapsulamento anafórico. Outro fator que dificulta a classificação é que os encapsuladores e a dêixis textual sumarizam um elemento dentro do próprio texto e a informação referida por esses dêiticos nem sempre está expressa de maneira pontual, mas diluída no discurso - caso clássico de encapsulamento anafórico. 
Retomando a diferenciação entre anáfora e dêixis, Santos e Cavalcante (2014), postulam que a característica peculiar às anáforas, que permite sua distinção em relação à dêixis propriamente dita, é justamente o fato de elas virem sempre associadas a uma âncora do cotexto que lhe serve de gatilho, permitindo, ainda, o encadeamento e a continuidade da referência. Ainda segundo as autoras, os casos de "dêixis impura", ou seja, a dêixis de memória, social e a textual, devem ser considerados como casos híbridos entre anáfora e dêixis, não devendo ser enquadrados em uma única categoria apenas, o que nos parece bastante coerente em termos de uma teoria mais simplificada.

De toda forma, objetivamos trabalhar com uma concepção sociodiscursiva da dêixis, em que tal fenômeno seja definido como um processo que requer o conhecimento de algumas coordenadas relacionadas ao contexto espaço-temporal, aos interlocutores e também aos conhecimentos compartilhados sociocognitivamente. Dessa forma, a relevância dos estudos deve recair sobre os sentidos e as diferenças que esses usos anafórico/dêiticos acarretam nos textos.

Os estudos sobre as relações anafóricas com demonstrativos dêiticos e a dêixis têm cada vez mais apontado para o entrelaçamento desses conceitos e para a tênue separação entre eles. Em se tratando dos processos referenciais, cumpre sempre destacar a importância dos dados do entorno sociocultural e situacional dos enunciadores, não só a importância das fontes presentes no texto, mas a forma como todos esses critérios vão auxiliar na representação mental do objeto de discurso. O processamento das relações requer uma complexa ativação de processos cognitivos que mobilizam conhecimentos na memória 
discursiva dos participantes da interação. Todo esse entrelaçamento de elos referenciais não se coaduna somente com o que está explícito no cotexto, mas também com o que está na memória discursiva e é ativado por meio de inferências.

\section{Dêixis temporal e pessoal nas notícias esportivas}

Como vimos, por sua capacidade de criar uma ligação entre o texto e a situação enunciativa em que se encontram os interlocutores, os processos de dêixis temporal e pessoal se distinguem dos anafóricos. Os elementos dêiticos exigem uma análise que deve focalizar a situação de comunicação, determinando um movimento em que é indispensável acionar conhecimentos compartilhados sobre a enunciação. É interessante observar, porém, como se comportam esses casos de dêixis em notícias esportivas, gênero textual fortemente situado no espaçotempo da enunciação.

O objetivo das notícias esportivas é sintetizar jogos de futebol, cujo resultado geralmente já é conhecido pelo leitor, que busca mais informações e um toque de curiosidade sobre o jogo em questão. Atualmente, as notícias esportivas não ficam restritas à publicação de resultados dos jogos e campeonatos, ampliando a possibilidade de cobertura para temas como a política dos clubes, situação financeira, entre outros, conforme aponta Coelho (2008). Em relação à linguagem, Barbeiro e Rangel (2006) destacam que o texto esportivo, de modo geral, detém maior liberdade no tratamento da matéria. Segundo os autores, na editoria de esportes, o humor e a leveza são perceptíveis, e o 
vocabulário, muitas vezes, consagra expressões populares, sendo mais criativo.

A seguir, destacaremos alguns dos exemplos mais recorrentes de dêixis nas notícias esportivas referentes aos jogos da Copa do Mundo de 2014 (cf. MORAIS, 2017): a dêixis temporal.

(1) Na verdade, tornou-se o anfitrião. O maior artilheiro da seleção uruguaia mostrou que jamais será coadjuvante de um time que depende muito dele. Luis Suárez estreou no Mundial ontem, marcou os dois gols da vitória por 2 a 1 sobre a Inglaterra, no Itaquerão, e manteve as chances de classificação para as oitavas de final. O resultado, porém, não significa o adeus da outra campeã do mundo, a Inglaterra. Tudo dependerá do jogo de hoje entre Itália e Costa Rica, no Recife. (FURTADO, Tatiana; KNOPLOCH, Carol; D’ERCOLE, Ronaldo. Suárez 100\%. Jornal O Globo. Rio de Janeiro, 20 de junho de 2014, p. 7).

No exemplo (1), o advérbio “ontem" faz uma remissão ao momento da enunciação, marcando uma relação temporal que toma como ponto de partida o dia em que a notícia foi enunciada e publicada. A marcação dêitica situa o instante, tendo em vista o momento do locutor, considerando a estreia do atacante Suárez no campeonato: uma data importante que marcou o retorno do jogador que estava afastado por uma lesão muscular e sua atuação na partida. Do mesmo modo, na sequência da notícia, o advérbio "hoje" implica uma noção de tempo que depende, para ser interpretada, do conhecimento do momento da enunciação. Dentro da notícia, essa fronteira temporal cumpre a função de informar ao leitor da ocorrência de um outro jogo, cujo resultado era importante para definir o futuro da seleção da Inglaterra na competição. Como a Copa do Mundo é uma competição com muitos jogos, principalmente na primeira fase, a 
classificação das equipes, muitas vezes, não depende só dos seus resultados, mas de uma combinação de resultados de outras partidas. Por isso, a referência temporal importa para situar o leitor nos jogos da competição.

Essas informações, bem como as datas dos próximos jogos, principalmente nas notícias que tratam de seleções favoritas ou de grande expressão no futebol, são comuns nas notícias esportivas e têm um importante papel de manter o leitor atualizado nos próximos compromissos de seus times e nas chances de classificação nas competições de que participam. É o que acontece, por exemplo, no exemplo (2):

(2) Na sexta-feira, a Alemanha volta a campo para encarar a França às 13h, no Maracanã, pelas quartas de final. (ILHA, Fávio. Batalha no sul. Jornal $O$ Globo. Rio de Janeiro, 1 de julho de 2014, p. 7)

Ao utilizar a expressão "na sexta-feira", o interlocutor se baseia na ideia de que o leitor tomará como ponto de partida a referência do dia em que a notícia foi publicada para compreender a coordenada dêitica temporal. O mesmo caso também acontece no exemplo (3), ao mencionar que o próximo jogo da Bélgica seria "no sábado":

(3) Com um gol de Kevin De Bruyne, e outro de Romelu Lukaku, os belgas venceram por 2 a 1, conquistaram a vaga, e agora enfrentam a Argentina no sábado, às 13h, em Brasília.

(BENJAMIM, Felipe. Bélgica bate Estados Unidos. Jornal O Globo. Rio de Janeiro, 2 de julho, Caderno de esportes).

Nesse exemplo, há também o advérbio "agora” que, a princípio, poderia não ser considerado como um caso de dêixis temporal, já que 
não tem como referência o momento em que se encontra o locutor. No entanto, poderíamos pensar em uma "dêixis temporal metafórica", já que marca uma relação temporal futura. Pistas textuais como o verbo no presente do indicativo, que, por não apresentar uma marca formal de tempo, pode indicar uma ação futura, e a expressão dêitica "no sábado" contribuem para entendermos esse "agora" como uma referência à próxima fase da competição. Dessa forma, o advérbio "agora” estabelece um marco temporal futuro, que projeta as ações da seleção Belga para frente na linha do tempo. Discursivamente, esse marco temporal anuncia que seu próximo adversário será a Argentina, seleção de maior prestígio do que a belga, sugerindo, implicitamente, que será um jogo difícil para os belgas.

A dêixis funciona, então, como um apontador enunciativo, convidando à projeção para atalhos que auxiliam na compreensão do texto, considerado, na perspectiva adotada, uma proposta múltipla de sentidos $(\mathrm{KOCH}, 2002)$. Nos próximos exemplos, os casos de dêixis criam, nas notícias, limites de tempo que diferenciam as ações descritas nas notícias esportivas.

(4) Esse Ronaldo, a Alemanha de Müller, artilheiro até agora no Brasil (3 gols), se deu ao luxo de deixar para depois... (AMATO, Gian. Chucrute na Bahia. Jornal O Globo. Rio de Janeiro, 17 de junho de 2014, p. 7)

$\mathrm{Na}$ notícia esportiva acima, sobre o jogo entre Alemanha e Portugal, fala-se da disputa da artilharia da Copa de 2014 e também do título de maior goleador em Copas, que, até aquele momento, pertencia ao jogador brasileiro Ronaldo. A disputa pela artilharia da Copa de 2014 era liderada pelo jogador alemão Thomas Müller. Desse modo, na 
expressão "artilheiro até agora", a locução adverbial "até agora" demarca uma espécie de fronteira, um limite cujo intervalo ocorre entre o momento da enunciação da notícia e o momento anterior no tempo, indicando que, até aquele momento da competição, o atacante alemão era o atleta com maior número de gols marcados. Com relação à disputa pelo título de maior artilheiro em Copas do Mundo, o duelo estava entre o jogador brasileiro mencionado acima e outro jogador alemão, Klose. Nesse sentido, o advérbio “depois", no final do excerto, constrói uma referência temporal para marcar que, daquele jogo em diante a artilharia do jogador brasileiro Ronaldo estaria ameaçada, já que ele se encontrava aposentado, e o jogador alemão ainda estava atuando na Copa de 2014. De fato, o brasileiro acabou perdendo essa disputa para o alemão.

No excerto (5), a expressão dêitica, além de criar uma delimitação temporal, promove uma demarcação no próprio texto, como se fosse um antes e depois na história da Holanda na Copa do Mundo de 2014.

(5) São necessários 45 minutos para a troca de lados em uma partida. Mas o intervalo esperado pela Holanda para virar o jogo durou quatro anos. No ciclo entre as Copas, os holandeses não suportaram o papel de coadjuvantes, enquanto a protagonista Espanha brilhava como a estrela campeã em sua camisa roja. Até ontem. (AMATO, Gian. Laranja amarga. Jornal O Globo. Rio de Janeiro, 14 de junho de 2014, p. 8)

A locução adverbial "até ontem", que encerra o parágrafo, toma como ponto de partida o momento da enunciação do texto em diante, delimitando um marco temporal. A partir desse jogo, a Holanda deixava a derrota sofrida na final da Copa de 2010 para vencer o seu rival, a Espanha, com uma ótima atuação, vencendo por um placar amplo de quatro gols de diferença. 
É interessante notar que esse parágrafo inicia o texto apresentando ainda a superioridade espanhola. No entanto, a partir da coordenada dêitica, há um novo momento discursivo, já que a continuidade da notícia passa a relatar a virada e superioridade holandesa sobre a Espanha. A expressão dêitica, nesse caso, funciona como uma demarcação de momentos diferentes no texto: o antes e o depois da seleção holandesa, que passou de equipe derrotada pela Espanha na final do mundial de 2010 para a equipe que impôs uma goleada na campeã mundial Espanha quatro anos depois.

No exemplo (6), preferimos analisar, conjuntamente, um caso de dêixis pessoal e também casos de dêixis temporal encontrados no mesmo texto. A notícia trata do jogo entre Argentina e Holanda, publicada no jornal Lance!, ocorrido na etapa semifinal da competição. Com a vitória da Argentina e a derrota do Brasil poucos dias antes, a comparação entre as seleções foi recorrente nos jornais.

(6) A Argentina vai fazer a final do mundial em nossa casa com a responsável pela maior humilhação de nossa história: a Alemanha. (...)

Certo é que, assim como o 8 de julho para os brasileiros, esse 9 de julho nunca será esquecido pelos argentinos. No dia da independência do país, eles ficaram a um jogo de conquistar o Brasil, a eternidade. Brasil, decime que se siente...

(PORTO, Marcio. Corrida para o tri. Jornal Lance! Rio de Janeiro, 10 de julho, p. 10).

O emprego do pronome possessivo de $1^{{ }^{\mathrm{a}}}$ pessoa do plural, em "nossa casa" e "nossa história", inclui interlocutor/leitor, presentes no segundo parágrafo do texto, em uma mesma situação de sofrimento e decepção pela derrota brasileira.

Há, no texto, uma oposição entre "nós" e "eles" revelada em alguns momentos da notícia, como na introdução, em que o jornalista 
começa dizendo que quem "veio ao Brasil" e fez "do país vizinho sua casa foram eles" - os argentinos. A partir desse momento, os argentinos são caracterizados como "eles" em oposição à expressão dêitica de pessoa, "nós" - os brasileiros. Desse modo, são criados dois grupos antagônicos no texto.

Já no final do texto, a derrota brasileira e a vitória argentina são enfatizadas, nesse parágrafo final, pelas referências temporais dêiticas: “o 8 de julho" e "esse 9 de julho". É interessante notar o emprego do artigo definido e do pronome demonstrativo nesses sintagmas. $\mathrm{O}$ artigo definido marca a data da derrota brasileira como conhecida do interlocutor, como um acontecimento histórico, já o pronome demonstrativo pode indicar que essa data específica a cujo jogo o texto remete tornou-se especial para os argentinos, que, no dia da independência do país, conquistaram a vaga para final do mundial. Além disso, o uso demonstrativo parece apontar para fora do texto, para o momento do acontecimento, tornando-o também histórico.

Cabe destacar a estratégia de abertura/encerramento da notícia, que se iniciou com os dêiticos pessoais marcando a rivalidade entre as duas seleções, e se encerrou com os dêiticos temporais, marcando a importância das datas para as duas seleções e também reforçando a rivalidade entre as duas equipes. Enquanto para os brasileiros a data era triste, para a Argentina era motivo de comemoração. Ou seja, a oposição nós/eles, criada no decorrer do texto, é reiterada pela oposição de resultados entre o 8 de julho da derrota do Brasil e o 9 de julho da vitória da Argentina. 
Essa rivalidade é bem marcada, principalmente no início do texto, em que se encontram as referências mais diretas, como a citação à música cantada pela torcida argentina ("Decime que se siente") e o uso dos pronomes, espalhando-se pelo resto da notícia com diversas alusões à seleção brasileira. É interessante notar que a notícia tratava do jogo entre Holanda e Argentina, mas, a todo momento, o jornalista refere-se à seleção brasileira. O fim da notícia volta à música citada no título e comenta como a vitória dos argentinos - retomados ao final pela anáfora direta pronominal "eles" - será lembrada, assim como a derrota do Brasil também será inesquecível para os brasileiros.

Ao agrupar os brasileiros com o uso do dêitico de pessoa "nós", o jornalista reforça o tom dramático da derrota, afinal sofremos a "maior humilhação da nossa história na nossa casa” - e a repetição do pronome nosso/a parece enfatizar esse efeito de sentido. A humilhação, portanto, não é da seleção brasileira, mas de todos os brasileiros, o que confere uma abordagem pessoal que visa ao apelo às emoções do interlocutor, como as análises têm demonstrado ser uma das características principais desse gênero.

Além disso, a oposição entre Brasil e Argentina criada no texto conversa com a rivalidade entre essas duas equipes, demonstrando, assim, uma das intencionalidades do interlocutor, que se apropria do conhecimento dessa rivalidade na construção do texto. Logo no subtítulo desta notícia, a frase "Brasil, decime que se siente" marca uma intertextualidade em relação a uma música entoada pelos argentinos durante a Copa, reforçando, para além das estratégias de referenciação, 
não só a oposição instaurada no interior do discurso, mas também como essa oposição foi apropriada em prol do projeto de dizer do texto.

De acordo com Maalej (2013), a dêixis de pessoa deve ser analisada conforme suas dimensões discursivas e ideológicas, como acontece com "nosso/nossa" no texto acima, pois, ao mesmo tempo em que inclui os brasileiros, exclui um outro agente, os argentinos. Trata-se de um indício da dimensão discursiva e ideológica de que trata Maalej, pois reforça estereótipos culturais e a rivalidade entre Brasil e Argentina, que se mostra bem clara no futebol, mas ultrapassa a esfera do esporte. Ainda de acordo com o referido autor, enquanto o usuário do "eu" está atrelado ao discurso como "egocêntrico", o "nós" constrói duas relações sociais diferentes, de inclusão e exclusão, pois, à medida que se define um conjunto como "nós", automaticamente, surge uma categoria de excluídos desse grupo. Portanto, os pronomes devem sempre ser entendidos tendo em vista outros pressupostos a respeito de quem está sendo definido como o "nós" e quem está sendo referido como "eles".

\section{Conclusão}

Percebemos, nos exemplos analisados por Morais (2017), que a dêixis, se analisada em uma perspectiva sociocognitiva e interacional, observando suas especificidades em um gênero textual como a notícia esportiva, comporta-se de maneira bastante peculiar. Retomando Santos e Cavalcante (2014, p. 243), lembramos que, em uma concepção 
de texto como processo, "precisamos analisar os exemplos observando esse processo sociocognitivo e interacional, complexo e abrangente".

Os advérbios temporais, por exemplo, nessas notícias esportivas, atuam como dêiticos cuja interpretação é feita a partir da data de publicação da notícia, que, provavelmente, deve ser uma data diferente da recepção desses textos por parte dos leitores. Porém, mais que isso, podem marcar uma mudança na condução da notícia, como vimos no exemplo (5). Já os dêiticos pessoais, conforme comprovamos no exemplo (6), colaboram para a argumentatividade do texto e, no caso em questão, enfatiza a polaridade marcada em campo entre brasileiros e argentinos.

Comprovamos, portanto, o que relembram Cabral e Santos (2016, p. 28): "o sujeito toma a língua como instrumento para realizar seus propósitos, insere-se no enunciado e constrói com ele objetos de discurso que instauram seus pontos de vista a respeito da realidade instaurada no discurso". O conceito de dêixis, então, precisa ser analisado considerando mais que os elementos dêiticos isoladamente, mais que a situação enunciativa imediata; é necessário observar as relações estabelecidas na interação, o que envolve, além dos interlocutores, o gênero textual, aspectos contextuais e sociointeracionais e as intencionalidades articuladas à construção argumentativa do texto.

\section{Referências}


APOTHÉLOZ, D. Papel e funcionamento da anáfora na dinâmica textual. In:

CAVALCANTE, M. M.; RODRIGUES, B. B.; CIULLA, A. (Orgs.). Referenciação. São Paulo: Contexto, 2003. p. 52-84.

BARBEIRO, H.; RANGEL, P. Manual do jornalismo esportivo. São Paulo: Contexto, 2006.

BENVENISTE, E. Problemas de Linguística Geral I. 3 ed. São Paulo: Pontes, 1991. BUHLER, K. The deictic field of language and deictic words. In: JARVELLA, R. J.; KLEIN, W. (Eds.) Speech, place and action: studies in deixis and related topics. New York: John Wiley and Sons, 1982. p. 9-30.

CABRAL, A. L. T.; SANTOS, L W. Dêixis pessoal e verbos na construção de um objeto de discurso argumentativamente orientado. Revista Conexão Letras, v. 11, n. 15,2016, p.25-37.

CAVALCANTE, M. M. Referenciação: sobre coisas ditas e não-ditas. Fortaleza: Edições UFC, 2011.

CAVALCANTE, M. M.; CUSTÓDIO FILHO, V.; BRITO, M. A. P. Coerência, referenciação e ensino. São Paulo: Cortez, 2014.

COELHO, P. V. Jornalismo Esportivo. São Paulo: Contexto, 2008.

CORNISH, F. Deictic, discourse deictic ans anaphoric uses of demonstrative expressions in English. Workshop Anaphoric uses of demonstrative expressions, System und Variation, 29th DGfS Annual Meeting, Universität Siegen, Germany (28th February-2nd March 2007) [mimeo].

EHLICH, K. Anaphora and deixis: same, similar, ou different? In: JARVELLA, R. J.; KLEIN, W. Speech, place, \& action studies in deixis and related topics. New York: John Wiley \& Sons Ltd., 1982. p. 315-338.

FILLMORE, C. J. Lectures on deixis. California: CSLI Publications Stanford, 1997 [1984].

FIORIN. J. L. As astúcias da enunciação: as categorias de pessoa, espaço e tempo. São Paulo: Ática, 1996.

FONSECA, F. I. Deixis, tempo e narração. Porto: Fundação Eng. A. de Almeida, 1992. 
HANKS, W. Incursões no campo dêitico. In: Língua como prática social.

São Paulo: Cortez, 2008. p. 204-227.

KOCH, I. Desvendando os segredos do texto. São Paulo: Cortez, 2002.

LYONS, J. Semantics: v. 2. Cambridge: Cambridge University Press, 1977.

MAALEJ, Z.A. Framing and manipulation of person deixis in Hosni Mubarak's last three speeches: a cognitive-pragmatic approach. Pragmatics, v. 23, n. 4, p. 633-659, 2013.

MARCUSCHI, L. A. A dêixis discursiva como estratégia de monitoração cognitiva. In: KOCH, I. G. V.; BARROS, K. S. M. (Orgs.). Tópicos em linguística de texto e análise da conversação. Natal: EDUFRN, 1997. p. 156-171.

MARMARIDOU, S. Pragmatic Meaning and Cognition. Amsterdam;

Philadelphia: John Benjamins Publishing Company, 20oo. p. 62-103.

MORAIS, M. M. Referenciação em campo: a construção de sentidos nas notícias esportivas. 2017. 181f. Tese (Doutorado). Rio de Janeiro: Faculdade de Letras, Universidade Federal do Rio de Janeiro, Rio de Janeiro, 2017.

PARDILLOS, M. A. C. Deixis as a reference to an alleged shared situation in persuasive discourse. Revista Alicantina de Estudios Ingleses, v. 8, p. 57-67, 1995.

SANTOS, L.W.; CAVALCANTE, M. M. Referenciação: continuum anáfora-dêixis.

Intersecções, Jundiaí, v. 12, n. 1, p. 224-246, maio/2014.

SCHIFFRIN, Deborah. Between text and context: Deixis, anaphora, and the meaning of then. Text, v. 10, n. 3, p. 245-270, 1990.

Recebido em 31/10/2017.

Aprovado em 22/12/2017. 